\title{
Penggunaan Vertikultur Teras Bangku untuk Pengembangan Budidaya Sayuran di KWT Mawar Bodas, Tasikmalaya
}

\author{
Selvy Isnaeni, Arif Malik Ramadhan \\ Universitas Perjuangan Tasikmalaya
}

Penulis korespondensi : selvyisnaeni@unper.ac.id

\begin{abstract}
Abstrak: Tanaman sayuran merupakan salah satu komoditas hortikultura yang produknya dimanfaatkan sebagai bahan makanan. Budidaya tanaman sayuran yang tepat akan memberikan hasil yang optimal. Kelompok Wanita Tani (KWT) Mawar Bodas merupakan organisasi yang berfokus pada pengembangan budidaya sayuran dan olahannya dengan memanfaatkan lahan terbatas. Melalui penerapan budidaya vertikultur juga memberikan solusi bagi anggota KWT Mawar Bodas untuk meningkatkan produksi. Adapun tujuan jangka panjang dari program ini adalah: Membantu potensi KWT Mawar Bodas dalam mengembangkan budidaya dengan produksi yang maksimal, dan Membantu KWT Mawar Bodas dalam menyelesaikan permasalahan dalam budidaya. Adapun target khusus yang ingin dicapai adalah budidaya vertikultur yang diterapkan dapat dikembangkan dengan tujuan untuk menambah motivasi bagi anggota KWT Mawar Bodas sekaligus untuk meningkatkan pendapatan anggota KWT Mawar Bodas. Hasil dari pengabdian ini adalah meningkatnya hasil budidaya kangkung secara konvensional KWT mawar bodas menghasilkan 6,4 kg dengan vertikultur teras bangku sebanyak 12,7kg, untuk tanaman Caisim secara konvensional menghasilkan $8.7 \mathrm{~kg}$, dengan vertikultur teras bangku sebanyak $17.5 \mathrm{~kg}$, dan untuk pakcoy secara konvensional 6,7 kg dan secara vertikultur teras bangku $13 \mathrm{~kg}$. Sehingga hasil budidaya sayuran KWT meningkat dan hasil kuesioner respon 100\% anggota KWT menyatakan bahwa penggunaan vertikultur teras bangku sangat membantu dalam budidaya dan terlihat rapi.
\end{abstract}

Kata kunci: budidaya, sayuran, vertikultur, kelompok wanita tani (KWT)

\begin{abstract}
Vegetable plants are one of the horticultural commodities whose products are used as food ingredients. Cultivating the right vegetable crops will give optimal results. Women's Farmers Group (WFG) Mawar Bodas is an organization that focuses on developing vegetable cultivation and its processed products by utilizing limited land. Through the application of verticulture cultivation, it also provides solutions for WFG members to increase production. The long term goals of this program are : helping the potential of WFG in developing cultivation with maximum production, and assisting WFG in solving problems in cultivation. The specific target to be achieved is that applied verticulture cultivation can be developed with the aim of increasing motivation for WFG members as well as increasing the income of WFG. The result of this dedication is that the conventional WFG cultivation yields $6.4 \mathrm{~kg}$ with 12.7 $\mathrm{kg}$ of verticulture, for caisim plants conventionally it produced $8.7 \mathrm{~kg}$, with $17.5 \mathrm{~kg}$ of verticulture, and for conventional pakcoy $6.7 \mathrm{~kg}$ and verticulture $13 \mathrm{~kg}$. So that the results of WFG vegetable cultivation increase and the results of the questionnaire response of $100 \%$ of WFG members state that the use of bench terrace verticulture is very helpful in cultivation and looks neat.
\end{abstract}

Keywords: cultivation, vegetable, verticulture, womens farmers group (WFG) 


\section{Pendahuluan}

Organisasi kemasyarakatan dalam bidang pertanian merupakan hal penting agar dapat memudahkan kerjasama antar petani. Kegiatan KWT meliputi budidaya pertanian skala rumah tangga, dari mulai penyemaian hingga pemanenan, pasca panen dan pengolahan hasil panen. Komoditas yang pernah diproduksi oleh KWT mawar bodas adalah kangkung, bayam, daun bawang, seledri dan cabai rawit. Komoditas tersebut ditanam di pekarangan yang menjadi posko atau homebase KWT Mawar Bodas, pada saat panen hasil produksi dimanfaatkan untuk dijual ke masyarakat sekitar dan sebagian dijadikan olahan keripik. Hasil panen yang didapat belum dapat memenuhi permintaan masyarakat sekitar karena budidaya yang belum maksimal, padahal KWT Mawar memiliki lahan yang cukup untuk dapat memaksimalkan budidaya sayuran. Sistem budidaya yang masih belum maksimal mengakibatkan lahan KWT banyak yang terbengkalai dan penjualan produk olahan belum terpenuhi. Jika budidaya dan pengolahan hasil panen kontinyu dan berkualitas, maka para anggota KWT dapat menjual komoditas hasil budidaya dan olahannya tersebut dengan sangat maksimal, dan menjadi sumber penghasilan bagi anggota KWT.

Terdapat data luas lahan pekarangan secara nasional sekitar 10,3 juta ha atau $14 \%$ dari seluruh luas lahan pertanian dan menjadi salah satu sumber potensial untuk menyediakan bahan pangan dan memiliki nilai ekonomi. Lahan pekarang saat ini belum dapat dimanfaatkan dengan baik sebagai areal pertanaman untuk komoditas pertanian, khususnya lahan pekarangan dapat dijadikan lahan penanaman tanaman obat keluarga, sayuran, ikan, maupun tanaman kebutuhan sendiri yang berpeluang menghasilkan sumber penghasilan tambahan bagi rumah tangga jika ditekuni dengan baik (Ariati, 2017).

Adaptasi teknologi budidaya pertanian perlu dilakukan agar dapat meningkatkan hasil produksi tersebut. Lahan pekarang yang terbatas masih dapat dimanfaatkan untuk kegiatan budidaya. Salah satu teknik budidaya yang dapat diterapkan pada lahan yang terbatas adalah teknik vertikultur. Budidaya dengan teknik vertikultur ini dapat diartikan sebagai teknik budidaya tanaman secara vertikal sehingga penanaman dilakukan secara bertingkat. Pemanfaatan teknik vertikultur ini memungkinkan untuk berkebun dengan memanfaatkan tempat secara efisien. Jenis-jenis tanaman yang dibudidayakan biasanya adalah tanaman yang memiliki nilai ekonomi tinggi, berumur pendek atau tanaman semusim khususnya sayuran seperti kangkung, bayam, seledri, caisim, bok choy, baby kalian, dan selada, selain itu tanaman 
sayuran yang memiliki sistem perakaran yang tidak terlalu luas. Bahan-bahan yang digunakan dapat berupa kaleng bekas, pot, botol dan gelas plastik, bambu dan pipa PVC (Kusmiati \& Solikhah, 2015).

\section{Metode}

Kegiatan pengabdian ini dilaksanakan di sekretariat KWT Mawar Bodas, jalan Sukanagara RT 03 RW 15, Kelurahan Kahuripan, Kecamatan Tawang, Kota Tasikmalaya. Pengabdian ini dilaksanakan dari bulan Juni - Desember 2020. Metode yang digunakan adalah pelatihan dan pendampingan dengan sasaran Kelompok Wanita Tani (KWT) Mawar Bodas. Anggota KWT diberikan pelatihan dan pembimbingan teknis mengenai budidaya vertikultur untuk berbagai jenis sayuran. Pelaksanaan melalui beberapa tahapan, diantaranya, yakni

1. Diskusi dan koordinasi

Kegiatan ini dilaksanakan sebelum memulai aktivitas budidaya vertikultur. Pada kegiatan ini menyampaikan semua kegiatan yang akan dilakukan dari awal hingga akhir termasuk outcome dari kegiatan pengabdian. Kegiatan diskusi juga dilakukan secara rutin setiap sebelum atau sesudah melakukan kegiatan.

2. Pelaksanaan budidaya vertikultur

Kegiatan dimulai dengan pembuatan vertikultur teras bangku dengan ukuran $4 \mathrm{x} 1$ meter. Pelaksanaan penanaman dilakukan dengan proses penyemaian terlebih dahulu, selama kurang lebih 7-10 hari. Setelah itu menyiapkan media tanam pupuk kandang, tanah, dan kompos dengan perbandingan 1:1:1. Pada vertikultur teras bangku, proses penanaman sayuran 92 polybag, dan untuk konvensional sebagai perbandingannya dengan luasan penanaman yang saya yaitu 46 polybag.

\section{Pemeliharaan dan Panen}

Pemeliharaan dilakukan dengan mencabut gulma yang tumbuh disekitar polybag dan jika ada hama dan penyakit yang menyerang langsung dilakukan tindakan secara mekanis, dengan membuang hama atau membuang tanaman yang terkena penyakit dan menggantinya dengan tanaman cadangan yang telah disiapkan. Pelaksanaan panen menyesuaikan dengan sayuran yang ditanam, sayuran yang ditanam adalah sayuran daun sehingga rata-rata waktu panen sekitar 35-45 hari. Pemanenan dilakukan dengan langsung mencabut sayuran dari media tanamnya, lalu dibersihkan dari sisa-sisa tanah dan ditimbang. 


\section{Monitoring dan Evaluasi}

Kegiatan monitoring dilakukan untuk mengetahui perkembangan pelaksanaan kegiatan yang dilakukan oleh mitra, dilaksanakan setiap minggu. Kegiatan evaluasi dilakukan setiap selesai panen untuk mengetahui hasil budidaya sayuran dan konvensional yang dilakukan apakah terjadi peningkatan, kendala atau hal lain yang masih dapat didiskusikan.

\section{Hasil dan Diskusi}

Pemenuhan kebutuhan pangan memiliki banyak kendala yang diakibatkan oleh perubahan kondisi lingkungan, alih fungsi lahan, dan semakin banyaknya serangan hama dan penyakit tanaman yang mengakibatkan penurunan produksi tanaman. Perlu dilakukan strategi baru dalam mengoptimalkan pemanfaatan lahan untuk meningkatkan kecukupan, ketahanan, dan kemandirian pangan masyarakat (Kusumo et al., 2020).

Pemanfaatan pekarang merupakan hal yang sangat membantu dalam ketersediaan pangan bagi masyarakat. Budidaya vertikultur merupakan alternatif budidaya dilahan yang terbatas. Penggunaan vertikultur dalam proses budidaya sudah banyak dilakukan mengingat semakin sempitnya lahan untuk bercocok tanam. Kegiatan diawali dengan diskusi agar para anggota KWT dapat menganalisis proses budidaya sayuran yang lebih efektif dan efisien agar dapat dilakukan pengembangan. Diskusi yang dilakukan seperti pada gambar 1, meliputi jenis sayuran yang banyak diminati oleh masyarakat sekitar KWT, sayuran apa yang banyak diproduksi sebagai olahan makanan dan jenis budidaya vertikultur mana yang paling efektif dan menguntungkan bagi anggota KWT. Diskusi ini juga untuk mencarikan solusi bagi para anggota yang mengeluhkan kegagalan budidaya dimasing-masing rumahnya, selain di lingkungan tempat KWT berkumpul.

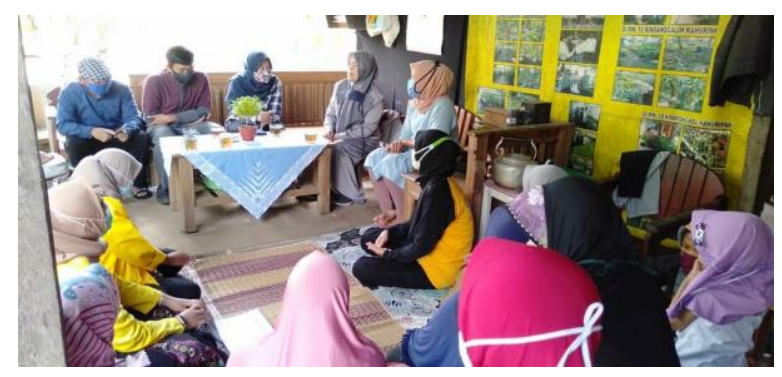

Gambar 1. Kegiatan diskusi budidaya sayuran 
KWT mawar bodas tidak hanya melakukan budidaya sayuran lalu menjualnya, tetapi juga melakukan proses pengolahan terhadap beberapa jenis sayuran yang dijadikan keripik, misalnya keripik bayam hijau, keripik bayam merah, keripik bawang, dan keripik kangkung. Budidaya selama ini dilakukan secara konvensional sehingga ketersediaan sayuran masih belum bisa mencukupi permintaan masyarakat sekitar dan kontinuitas dari ketersediaan sayuran belum dapat dipastikan. Kegiatan kedua yang dilakukan di KWT mawar bodas adalah pembuatan vertikultur teras bangku agar lahan sempit dapat dimaksimalkan. Vertikultur teras bangku dibuat dengan ukuran 4 x 1 meter dengan 4 tingkatan seperti pada Gambar 2 .

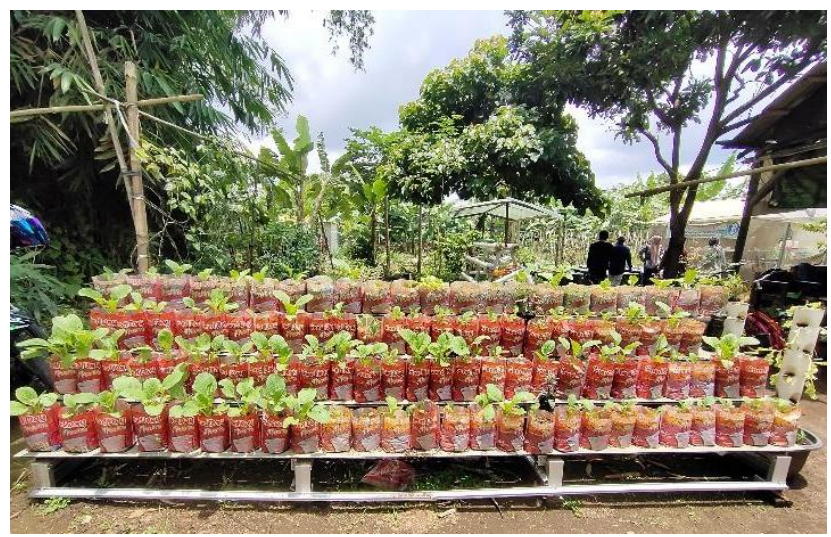

Gambar 2. Vertikultur teras bangku

Budidaya yang dilakukan di KWT tidak hanya satu kali dan pada satu komoditas sayuran saja, tapi diuji cobakan pada beberapa jenis sayuran, seperti kangkung, caisim, dan pakcoy. Budidaya diawali dengan melakukan penyemaian, dan penyiapan media tanam. Media polybag yang biasanya digunakan untuk budidaya digantikan dengan memanfaatkan plastik bekas kemasan kopi. Dengan penggunaan plastik bekas kopi juga dapat membantu dalam mengurangi sampah plastik, selain itu pembelian polybag juga dapat dikurangi. Sehingga dapat lebih menguntungkan bagi para anggota KWT dan lingkungan sekitar. Media yang sering digunakan untuk budidaya sayuran adalah campuran antara, tanah, pasir, dan pupuk kandang atau kompos dengan perbandingan yang sama. Budidaya dengan metode vertikultur memiliki banyak keuntungan yaitu efisien dalam penggunaan lahan, mudah dalam pemeliharaan, penghematan penggunaan pupuk, praktis dan mudah dalam kontrol pertumbuhan gulma, dan dapat dipindahkan dengan mudah, serta hemat air dan menambah estetika (Diwanti, 2018). 


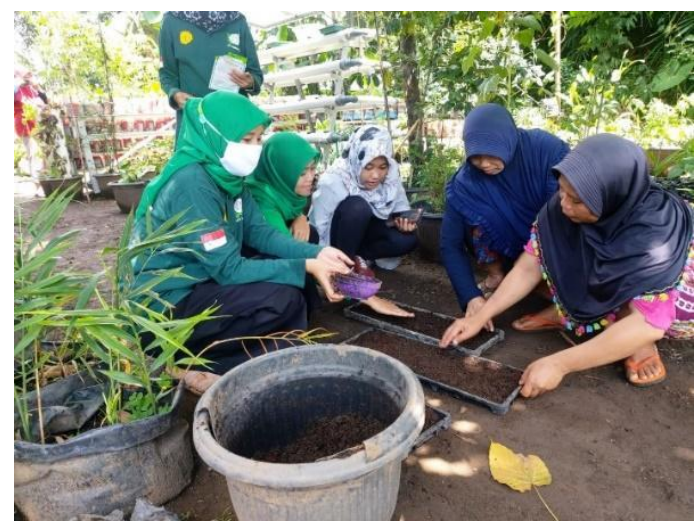

Gambar 3. Proses Penyemaian benih sayuran

Penggunaan vertikultur yang diarahkan kepada KWT mawar bodas adalah penggunaan vertikultur paralon, teras bangku dan penggunaan botol bekas. Namun untuk penerapan yang paling efektif dan efisien adalah penggunaan vertikultur teras bangku. Dapat dilihat pada diagram 1 hasil yang didapatkan dari penggunaan vertikultur teras bangku. Terdapat dua kali proses budidaya yang dilakukan selama uji coba vertikultur teras bangku, yaitu budidaya kangkung, caisim dan pakcoy.
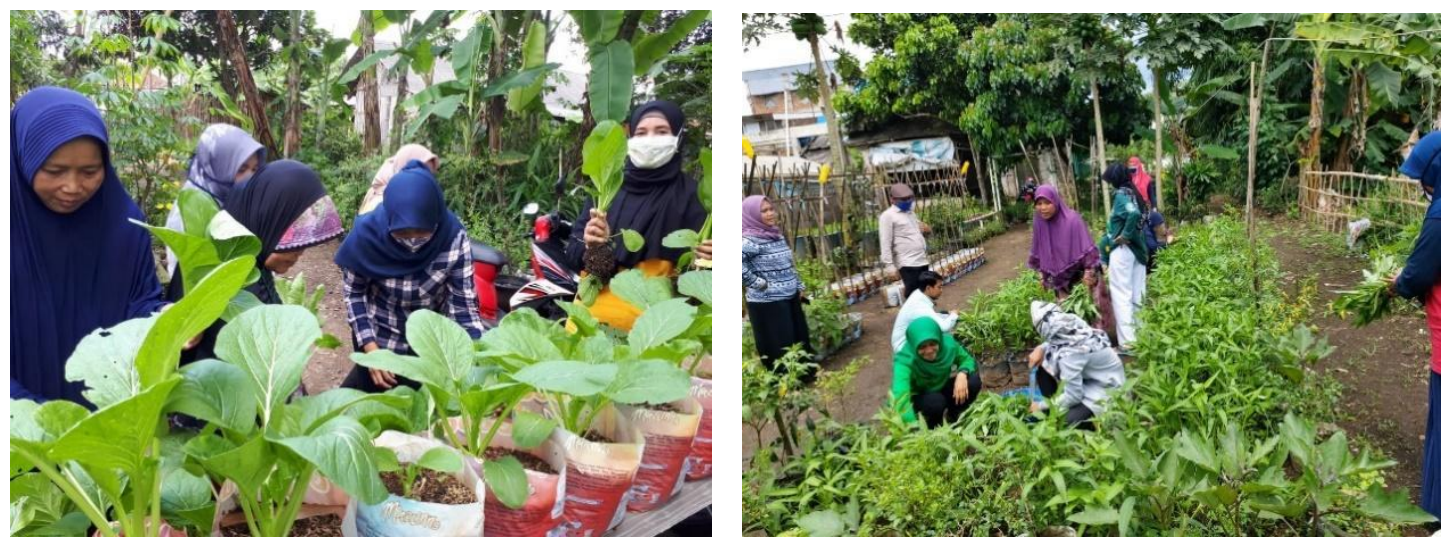

Gambar 4. Proses panen vertikultur dan konvensional

Dari hasil percobaan dapat dibandingkan bahwa hasil panen dari kangkung dan sawi meningkat 2x lipat dari panen secara konvensional, untuk budidaya kangkung yang secara konvensional menghasilkan $6,4 \mathrm{~kg}$ dari total 46 polybag, sementara untuk metode vertikultur teras bangku dari total 92 polybag dapat menghasilkan $12,764 \mathrm{~kg}$. budidaya caisim juga demikian, budidaya caisim secara konvensional dari 46 polybag menghasilkan $8.768 \mathrm{~kg}$ caisim, sementara penggunaan vertikultur teras bangku dapat menghasilkan $17.512 \mathrm{~kg}$ dari 92 polybag, dan untuk panen pakcoy untuk konvensional menghasilkan $6,720 \mathrm{~kg}$ dan pada vertikultur menghasilkan 13,024 kg sehingga para anggota KWT dapat menghasilkan sayuran lebih 
banyak untuk dapat dijual maupun diolah menjadi keripik.

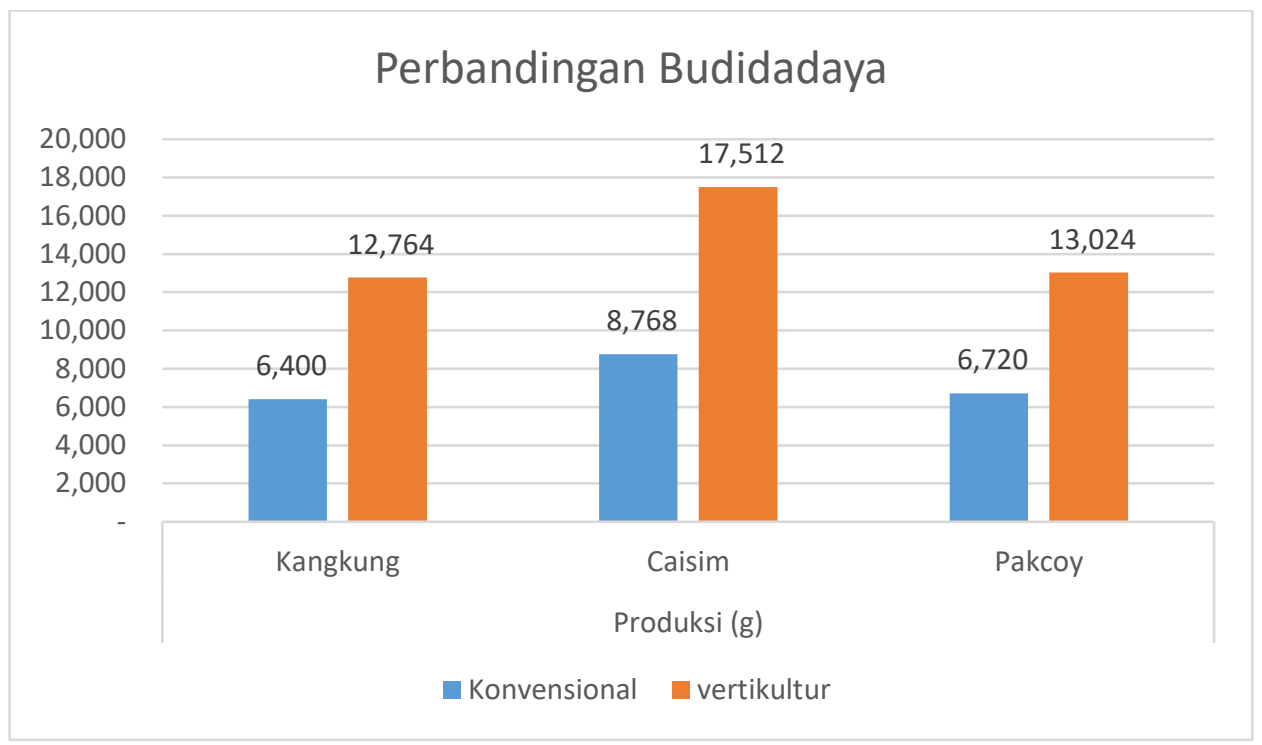

Diagram 1. Perbandingan budidaya kangkung, Caisim dan Pakcoy

Kegiatan yang telah dilaksanakan memberikan dampak positif pada kemajuan kegiatan KWT. Metode budidaya yang dikehendaki oleh anggota KWT dan menghasilkan produksi yang lebih baik adalah budidaya dengan menggunakan vertikultur teras bangku, dibandingkan dengan hidroponik, vertikultur paralon dan juga konvensional seperti pada diagram 2. Selain itu menurut anggota KWT mawar bodas, dengan penggunaan vertikultur teras bangku selain dapat menambah produksi juga dapat menjadikan pekarangan, atau lahan produksi KWT menjadi lebih rapi dengan perawatan yang lebih mudah.

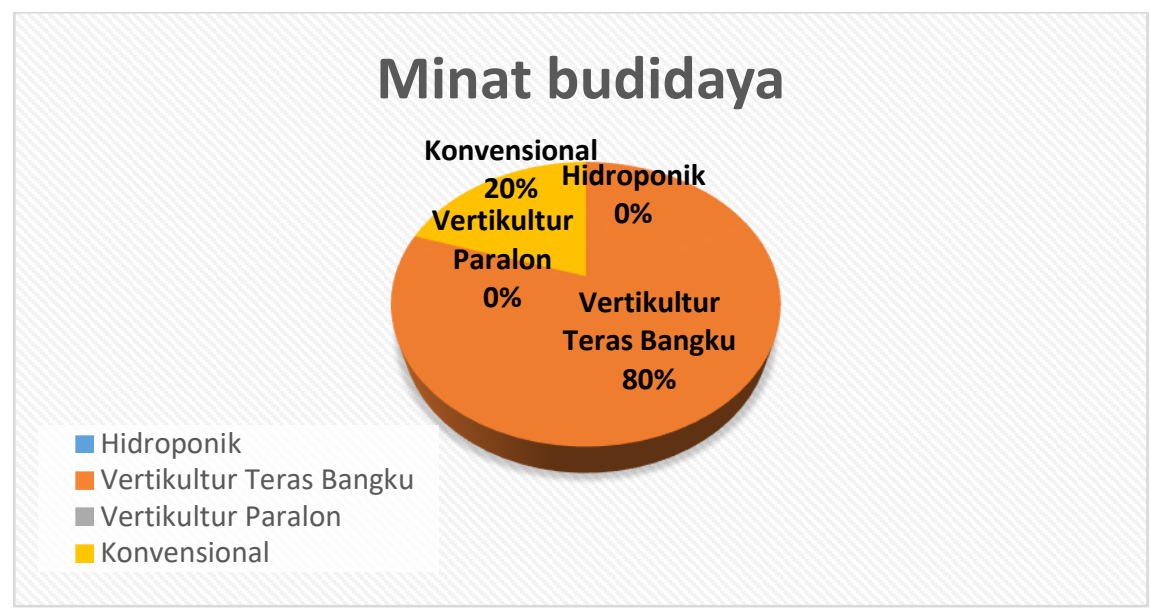

Diagram 2. Minat budidaya anggota KWT 


\section{Kesimpulan}

Bentuk pengabdian yang telah dilaksanakan adalah penyuluhan dan pelaksanaan budidaya vertikultur teras bangku. Hasil yang didapatkan adalah budidaya vertikultur teras bangku dapat membantu produksi sayuran di KWT meningkat. Budidaya kangkung secara konvensional menghasilkan 6,4 kg dari total 46 polybag, untuk metode vertikultur teras bangku dari total 92 polybag dapat menghasilkan 12,764 kg. Budidaya caisim konvensional dari 46 polybag menghasilkan $8.768 \mathrm{~kg}$ caisim, penggunaan vertikultur teras bangku menghasilkan $17.512 \mathrm{~kg}$ dari 92 polybag, dan untuk pakcoy konvensional menghasilkan 6,720 kg dan pada vertikultur menghasilkan $13,024 \mathrm{~kg}$.

\section{Ucapan Terima Kasih}

Penulis menyampaikan terimakasih kepada Rektor dan Ketua LPPM Universitas Perjuangan yang telah mendukung seluruh pembiayaan kegiatan pengabdian ini melalui skema hibah internal Pemberdayaan Masyarakat Desa Binaan (PMDB) tahun 2020 dengan no kontrak: 259/ST/LP2M/UP/08/2020.

\section{Daftar Referensi}

Ariati, P.E.P. 2017. Produksi Beberapa Tanaman Sayuran dengan Sistem Vertikultur di Lahan Pekarangan, Jurnal Agrimeta, 7(13), 76-86.

Diwanti, D.P. 2018. Pemanfaatan Pertanian Rumah Tangga (Pekarangan Rumah) dengan Teknik Budidaya Tanaman Sayuran Secara Vertikultur, Martabe: Jurnal Pengabdian Kepada Masyarakat, 1(3), 101.

Kusmiati, A., \& Solikhah, U. 2015. Peningkatan Pendapatan Keluarga Melalui Pemanfaatan Pekarangan Rumah dengan Menggunakan Teknik Vertikultur, Jurnal Ajie, 4(2), 94-101. Kusumo, B., Andriani, R., Sukayat, Y., Heryanto, M.A., \& Wiyono, S.N. 2020. Budidaya

Sayuran dengan Teknik Vertikultur untuk Meningkatkan Ketahanan Pangan Rumah Tangga di Perkotaan, Jurnal Dharmakarya, 9(2), 89-92. 